\title{
Biophysics Of Brain Activity. Brain Activity In The Development Of "Creative Thinking" "Mind Map"
}

\author{
${ }^{1}$ A.G.Ganiev, ${ }^{2}$ Z.Sh.Abdunazarova \\ ${ }^{1}$ Candidate of Physical and Mathematical Sciences, Associate Professor; Director of Shakhrisabz branch of \\ Tashkent State Pedagogical University, Uzbekistan. \\ E-mail: fizika1011@mail.ru \\ ${ }^{2}$ Teacher of Shakhrisabz branch of Tashkent State Pedagogical University, Uzbekistan. \\ E-mail: Zulayxoabdunazarova83@mail.ru
}

Article History:Received:11 January 2021; Accepted: 27 February 2021; Published online: 5 April 2021

\begin{abstract}
The article provides information about the human brain, including its energy consumption, the functional functions of its parts, the biophysics of the sensory channels of the visual mechanism. The channels of movement of information through the neural fibers of the brain, the description of "unusual" ideas that lead to new and "creative thinking", the importance of the method of "comparative learning" in the development of "imagination" and "creative thinking" were discussed. The "specialty-related" mind map of the cerebral hemispheres serves to visualize and develop the activity of the right hemisphere of the brain, which is responsible for "creative thinking". To activate the right hemisphere of the brain, it is recommended to use emotional "mind map", Uzbek folk tales, folk sports, folklore. The "mind map" of the sensory channels encourages feedback on the functioning of the human sensory organs, the mechanism of information reception, and opportunities to increase the efficiency of this process. It serves to visualize the mechanism by which 'imagination' is formed.
\end{abstract}

Key words: Sight, hearing, smell, feeling, taste, neurons, dendrites, axons, synapses, imagination, intuition, emotions, creative thinking, fluently thinking.

\section{Introduction.}

Although the brain has a mass of only $2 \%$ of the mass of the human body, it consumes $20 \%$ of the oxygen circulating in the blood. Eighty percent of it is water, so the brain is the first to feel thirsty [1]. The brain uses about $10 \mathrm{~J}$ of energy per second to work fully. When great things are done, the energy consumption of the brain increases. For example, when Newton created the "law of universal gravitation" or A. Einstein's "theory of relativity", it is not surprising that the energy consumption of the brain reached $30 \mathrm{~W}$. The brain controls our thinking, memory, speech, movement of our limbs, and the activity of all the organs in our body. For example, let's look at the physiology of the memory process. Memory consists of four processes: a) memorization (or coding); b) storage; c) recovery (remembering) d) forgetting [2].

a) All received data is coded. From a physiological point of view, coding is the conversion of external energy into our sensory organs into specific electromagnetic field energy and electromagnetic waves, or signals. These signals travel along neuron fibers.

b) The better the data is encoded, the better it will be stored in memory. Usually, the information received on the basis of reasoning and comprehension is well stored in the memory. In this point of view data visualization is important. It is especially effective in teaching physics, chemistry and biology.

c) If the new information matches the information in the brain, the brain will immediately compare it with the previous one. If they do not match, the traces of neurons formed in the early stages of data reception will change.

d) The final step in processing the received data is forgetting. The brain sorts information according to its importance. Some are ignored and we forget them quickly.

The brain can store from 3 terabytes to 1,000 terabytes of data. The 900-year-old British National Archives contains only 70 terabytes of material [1].

Man has always strived for perfection, that is, to think deeply, to strengthen his memory, and to keep his body healthy and beautiful. These are related to improving brain function.

Brain structure and function.

The brain is divided into two parts: the left and right hemispheres [3]. They are connected by a fiber bundle that transmits data from one side to the other. Each hemisphere is also divided into four parts: the forehead, the temples, the upper part, and the neck. They are responsible for the following activities: forehead - speech, movement, complex thinking; temporal lobe - hearing and smell; the upper part - feeling and taste; The neck interprets vision (color, light, movement) [4].

The most complex processes in data processing happen in the cerebral cortex.

The cerebral cortex is $3 \mathrm{~mm}$ thick and consists of 6 layers. It has an average surface area of 2,200 $\mathrm{cm}^{2}$ and more than 10 billion neurons [5]. 
Although man has many sensory channels, since ancient times there have been five senses that receive information mainly from the outside world: - sight, hearing, smell, touch, and taste.

Sensory organs begin with cells that record signals. These signals depend on the type of sensation can be: electromagnetic waves - in sight, in perception; mechanical waves in hearing; physical taste and chemical smell. However human senses are limited in that they can see light waves from $v=4 \cdot 10^{14} \mathrm{~Hz}$ to $v=7.5 \cdot 10^{14} \mathrm{~Hz}$ and hear $v=16-20000 \mathrm{~Hz}$ sound waves. A short-term (about $1 \mathrm{~ms}$ ) change in the potential difference in a neuronal membrane, or muscle cell, generates an action potential or an electrical impulse, which is transmitted to the nerve fibers connected to the brain. Then the messages travel to the spinal cord and then to the brain. The speed of movement of electrical signals from the nerve fiber to the brain is $274 \mathrm{~km} / \mathrm{h}$. Humans have 31 pairs of spinal nerve fibers, all of which are responsible for transmitting sensory messages. In addition, 12 pairs of cranial nerve fibers are involved in this function [4].

The question arises as to how sensory cells record messages. The intuition, taste, and smell receptors contain sensitive proteins that, when odor is produced (when molecules of matter appear in the environment), open up and positively charged ions enter the cell. This results in depolarization, that is it occurs a disruption of polarization in the cell. The return of the cell to its original state results in the emission of electromagnetic waves, or signals. The resulting signal is transmitted to the brain. The hearing and visual receptors work in the same way, and external influences cause the cells in them to shift their charges and create a potential difference. The frequency of the action potential transmitted from the nerve fibers (electromagnetic wave energy) is determined by the energy of the received waves. If 20-40 signals per second are transmitted, it is considered weak, $50-70 \mathrm{~Hz}$ is considered moderate, and $100 \mathrm{~Hz}$ is considered strong. Signals with a frequency higher than $100 \mathrm{~Hz}$ can be frustrating. The information is processed in the brain and passed to the cerebral cortex. The senses are always in touch with each other. For example, sight also affects hearing [4].

The light from the object is received by the eye, and the eyeball creates an inverted image of it on the retina. This retina is made up of two types of cells: the cone and the rod, which convert the (visible electromagnetic radiation into the energy of the electromagnetic waves. There are about seven million cones, of which there are three types: red, green, and blue. Light waves excite the atoms of tube-shaped cells depending on the wavelength (wave energy). When atoms return to their ground state, electromagnetic waves (signals) are emitted. From this combination of signals, the brain produces different colors. When the luminosity (the flux of photons) decreases, the activity of the tubular cells stops and the rod-shaped cells start working. The rod-shaped cells, on the other hand, are so numerous in the eye, around a hundred million, that they are usually responsible for shadowing images and sending signals to the brain [6].

The cell that excites electrical signals in the brain is made up of neurons and gilial cells that connect neurons.

A neuron is a brain cell that receives, stores, and transmits information using chemical signals and electrical impulses. The human brain is made up of about 90 billion neurons, which are connected to each other more than 10,000 times by branches (axons and dendrites) and synapses [7]. The mental development of the brain is determined by the large number of such connections.

Dendrites are branches of neurons that receive information. Each neuron has several dendritic branches. The more dendrites a neuron has, the better it receives and processes information.

An axon is a branch of a neuron that transmits signals to other nerve cells as well as to cells of muscles and internal organs.

A synapse is an axon of one neuron and a dendrites of another neuron, which connects the bodies of neurons. It acts as a specific relay that transmits signals from one neuron to another. When electrical signals reach the synapse, a special substance is released that wraps around a small bubble and acts as a mediator between the two neurons [4].

It is the hormone dopamine, which is responsible for "pleasure, motivation and learning." It is the biological ancestor of norepinephrine and adrenaline, arousing curiosity. Dopamine and serotonin stimulators [8].

Dopamine increases curiosity in the educational process. Interested information is better assimilated. Improves the child's ability to remember, learn, make decisions. It increases the feeling of happiness, the tendency to creativity. Dopamine acts as a neuromediator in the brain, helping to transmit signals from one neuron to another through the central nervous system and acting on the brain nucleus. This part of the brain interacts with the centers responsible for passion, memory, curiosity, and motivation[9].

To stimulate dopamine production: one should eat almonds, pistachios, green tea, seafood, cabbage, apples, bananas, strawberries, peaches. He should be physically active and sleep normally. Achieving goals, thinking about good things, and remembering sweet memories also improve dopamine production.

Inactivity, obesity, and bad habits (nicotine, caffeine, alcohol, etc.) negatively affect the brain's production of dopamine.

The movement of the arms and legs is very important for brain development. The human brain is designed to walk $19 \mathrm{~km}$ a day. This is why physical effort is needed to improve mental ability. Physical activity ensures that the human brain is supplied with blood, that is, oxygen to clear the brain of glucose and toxins, and promotes the production of a protein that communicates with neurons in the brain [2]. 


\section{Brain activation factors.}

Information travels through the neurons of the brain, and they are thought of as channels of motion[10]. Subsequent data moves from the previously opened channel, and over time, this channel becomes dominant and becomes the main path. This means that all similar information is stored in this "main path" (the trace in the brain), that is, in memory. It's a realising information. This is how comparing new information with what is in the brain ("comparative learning"). If there were no such main path, and if there was a separate path for each piece of information, the brain would be full of paths.

Comparative teaching is the most effective method in the education system. This feature is unique to man and is one of the main factors that make him superior to the computer. Various "models" have been devised to use this method. For example, in physics, such concepts as "material point", "absolutely solid", "ideal gas", "point charge" can be cited as such a model. "Comparative learning" is a good way to activate the brain and develop "imagination" and "creative thinking" skills.

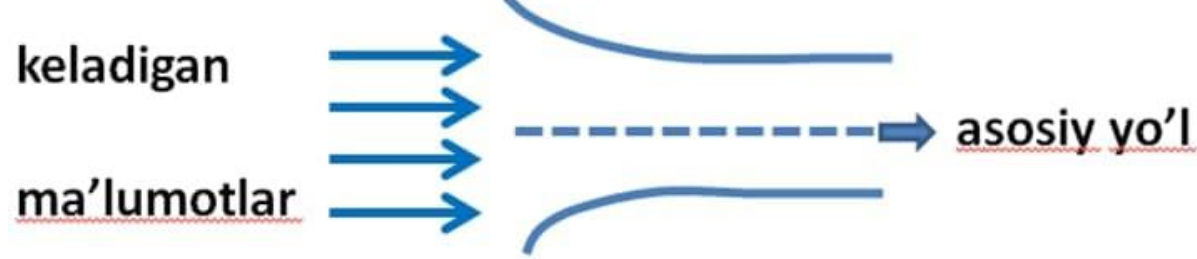

What happens if there is a discrepancy in the data? It separates the trails(the traces are separated from the main trail) from the main road. Perhaps these trails will become one of the main routes in the future. If there is no new information to strengthen it, it will disappear over time. That is, this information is forgotten.

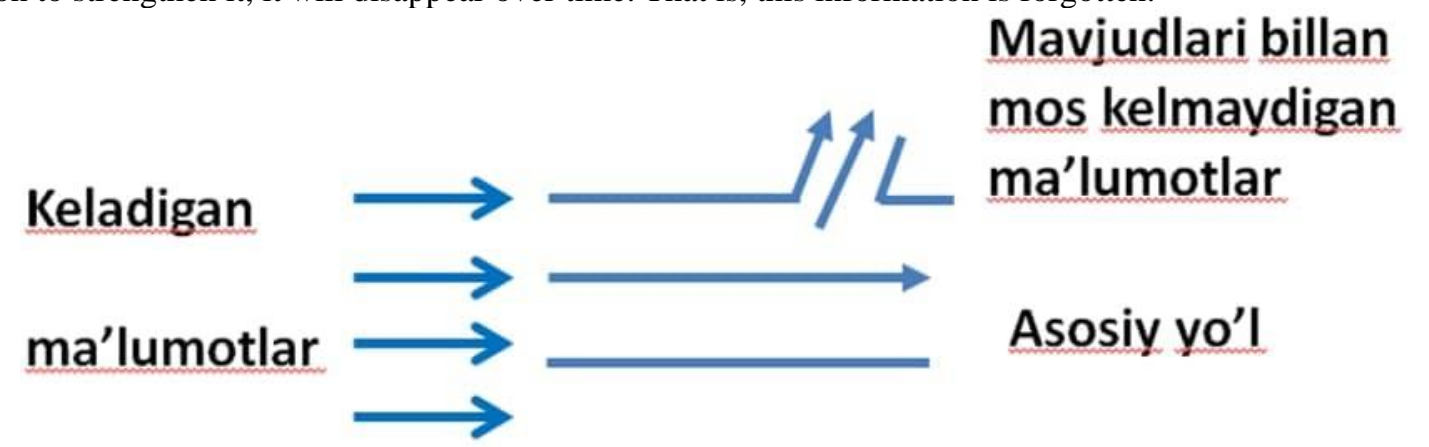

How do you describe unusual ideas?

In this case, the information about the ideas does not move along the main roads, but appears in a transversal peripheral branch. They can strengthen the existing path and become a key part of it. An example of this is the development of Einstein's classical theory of relativity to create a "special theory of relativity" suitable for high speeds. If the idea is insignificant, it will not change the main trace and will be forgotten by itself.

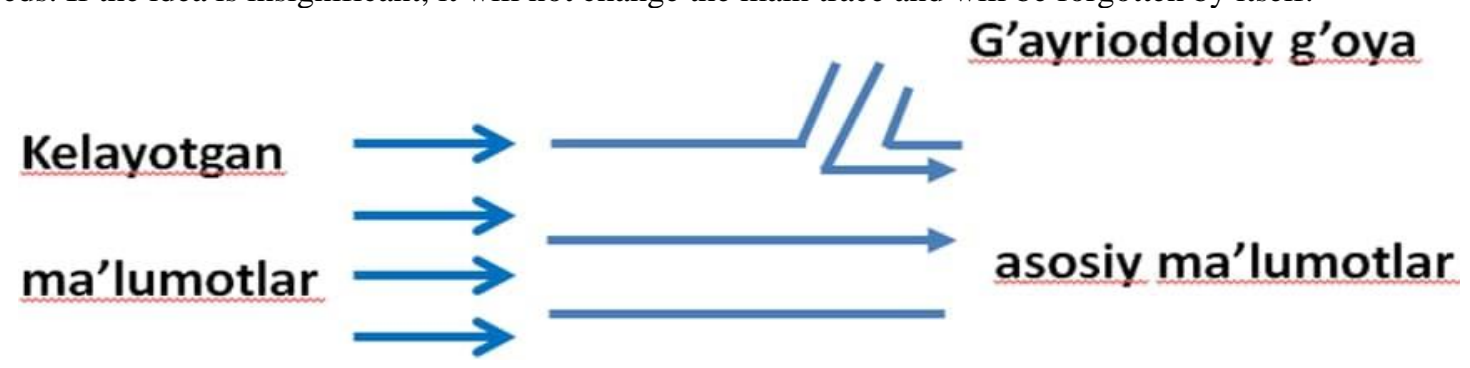

Unusual ideas are usually born in "creative thinkers". In practice, most qualified professionals know how to analyze data and think logically. In general, logical thinkers have always been valued and they have also achieved great success. Children with such characteristics are good at math and do well in school. Those who live with sweet dreams and unexpected offers under the influence of various perceptions are considered dreamers and are not encouraged in society.

For example, A. Einstein was a carefree and dreamy child. He did not even know simple mathematical operations. His teachers underestimated his intellectual potential.

According to Sperry Roger's "discovery of the hemispheres of the brain in relation to specialties," intuition, imagination, and "creative thinking" are the products of the right hemisphere of the brain[3]. 


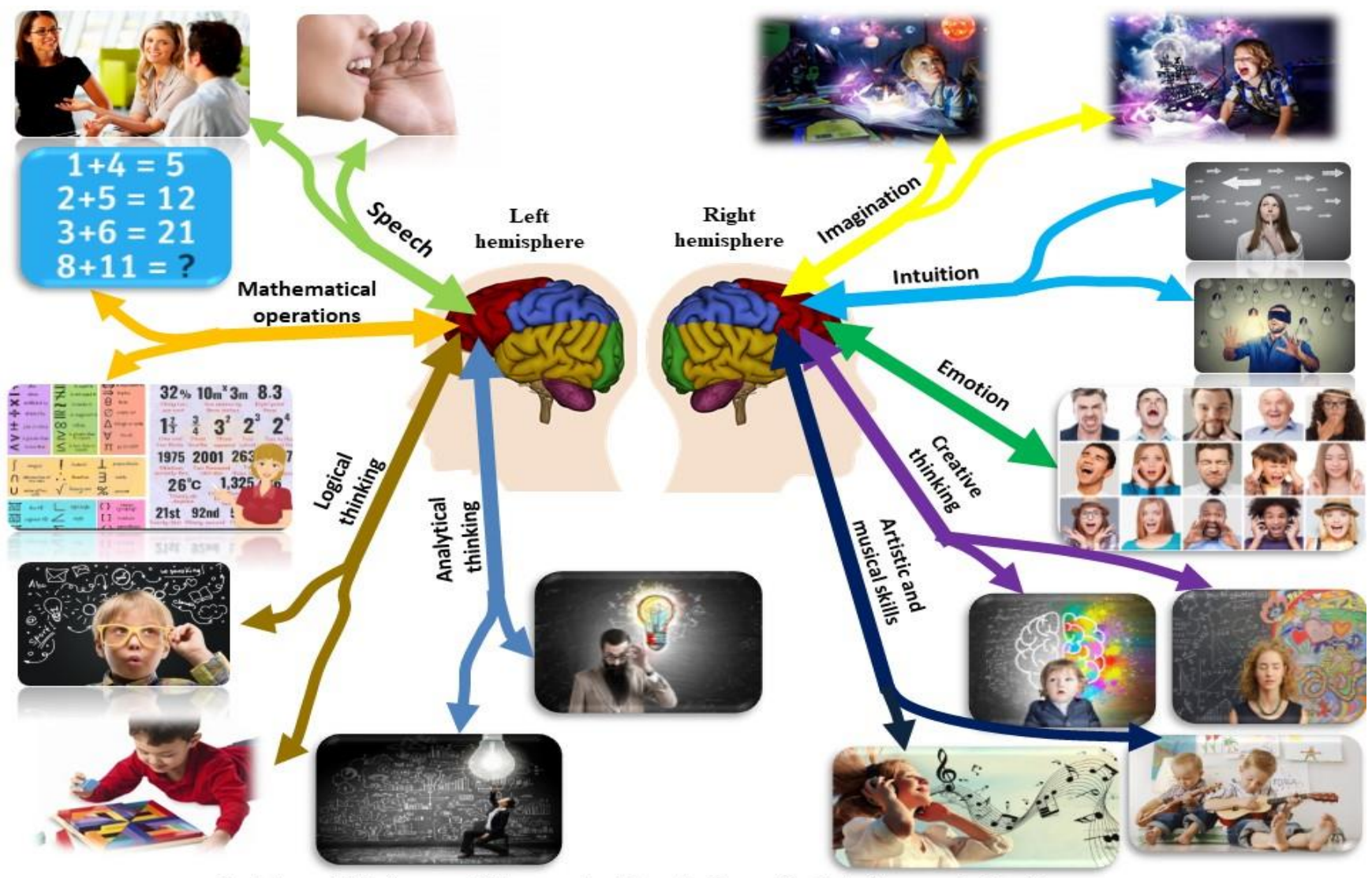

1-picture. Mind map of the cerebral hemispheres "related to specialties"

It is related to the creative activity of parts of the cerebral hemispheres.

Most adults can't even imagine their dreams. Because they cannot use the right hemisphere of their brains effectively. More precisely, they did not do it from a young age. In practice, the right hemisphere of the brain can be activated in a variety of ways to exploit its latent potential, especially the imagination. Activating the right hemisphere of the brain, coordinating the activities of both hemispheres, and developing "creative thinking" skills can increase brain productivity. The cerebral cortex allows both hemispheres to work together. The interaction of the left and right hemispheres, that is, the interaction of the cerebral hemispheres, is called "complete thinking." People with active hemispheres of the brain are called "ambidexters" (ambidextry - Latin, ambi - both, dexter - right) - their speech is fluent and beautiful, they are good at calculations, they are passionate and always creative[11].

Many famous scientists were ambidexters. These include Leonardo de Vinci, Julius Caesar, Benjamin Franklin, Nikolai Tesla, Andrei Sakharov, Tom Cruise.

In order to activate both hemispheres of children's brains, it is possible to use folk tales, folk sports games, folklore "mind map" and improve their "creative thinking".

In the process of "creative thinking" connections are made between brain cells. This means that the brain has its own "mind connections", a special internal "mind map"[12].

The same active development of the cerebral hemispheres is the most ideal. The following are good examples:

While the left hemisphere of the brain is active in music education, the creation of a musical work that is born under different perceptions is a product of the right hemisphere[8].

- If the poet uses the right hemisphere to make analogies and find elements of fantasy when writing a poem, the left hemisphere serves to express these feelings fluently in words.

- When drawing the structure of a building, the architect uses the function of the right hemisphere to determine its spatial location and aesthetic appearance. But all calculations are done using the left hemisphere.

- While E. Rutherford used the right hemisphere to represent the planetary model of the atom, and the Bohr proposed the pastulants, the analysis of the experiments and calculations to prove their correctness were carried out using the left hemisphere.

- The appearance of the new model of the car is imagined in the right hemisphere of the designer's brain before production. Then the technical parameters are calculated using the left hemisphere.

According to experts, from the age of five, the hemispheres of children's brains begin to separate into "specialties". The ability to learn a language plays an important role in this. This means that from the age of 
five, children can be taught the elements of "creative thinking". Einstein's interest in science began at the age of five, when his father showed him a compass. He also loved to play the violin.

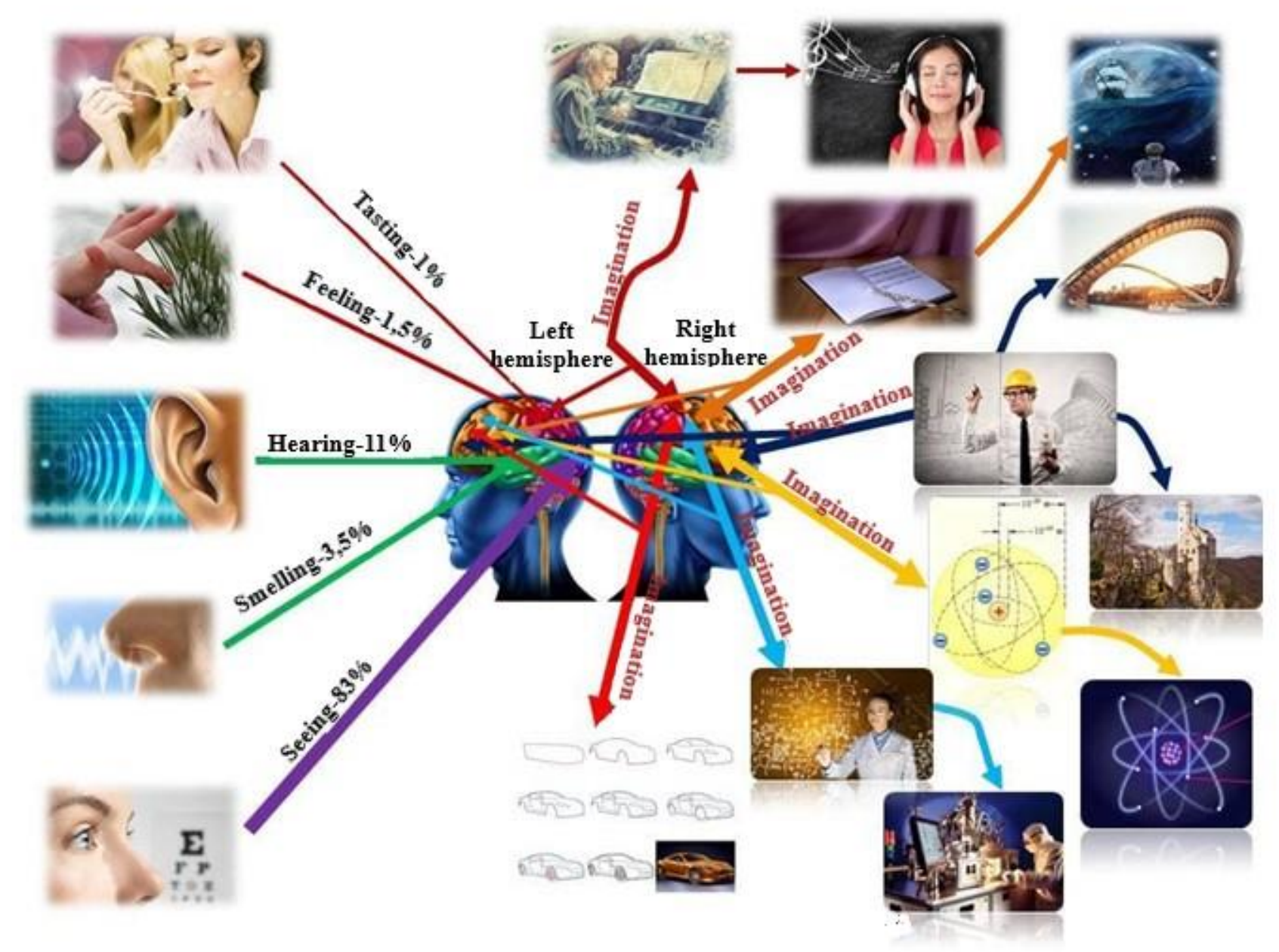

2-picture. "Sensor channels" Mind map.

This mind map shows that the imagination perceives food and based it on the formation of "creative thinking" in the right hemisphere of the brain.

It shows that the information coming from the sensory channels is perceived by the left hemisphere of the brain and describes the exact shape of the object. Based on this information, elements of "creative thinking" are formed in the right hemisphere of the brain.

These Mind maps help to deepen the knowledge of brain activity, the functional specialties of the hemispheres, on the one hand, and the development of "imagination" and, consequently, "creative thinking" skills on the other.

The Mind Map is one of the most effective ways to develop students' 'imagination' and 'creative thinking' skills [13.14]. Its creation allows the birth of new ideas, concentration and the conversion of verbal information into visual information, which can be used effectively in the educational process $[15,16]$.

\section{Conclusion}

- The brain, which makes up $2 \%$ of the human brain, is $80 \%$ water and consumes $20 \%$ of the oxygen circulating in the blood. It consumes an average of $10 \mathrm{~J}$ of energy per second. The productivity of the brain is determined not by its weight, but by the number of connections between its cells. - The brain receives information from the outside world through sight, hearing, smell, taste and touch. This information triggers signals (electromagnetic waves) in the sensory organs, which travel to the brain via neurons in the brain cell.

- The brain receives information from the outside world through sight, hearing, smell, taste and touch. This information triggers signals (electromagnetic waves) in the sensory organs, which travel to the brain via neurons in the brain cell. 
- A neuron is a brain cell that receives information and converts it into electromagnetic waves (signals). Neuron fibers that transmit signals can be thought of as channels of motion. In this case, the new information is compared with the existing ones in the brain and described as additional paths, and unusual ideas as crossnetworks. Such 'comparative learning' helps to develop one's 'imagination' and, consequently, 'creative thinking' skills.

- In order to store information well in memory (especially in teaching of physics, chemistry, biology), it is necessary to visualize them. Because the brain has a natural need to identify images. The use of "intelligence maps" in education for this purpose is very effective.

- The mind map of the cerebral hemispheres related to the profession helps to visualize the activity of the brain, to "imagine" its activity and to develop "creative thinking".

- This mind map visually shows what activities are appropriate for the formation of "full thinking" and the activation of the right hemisphere of the brain.

- It is recommended to activate the right hemisphere of the brain, to perform "ambidexter" exercises to develop "creative thinking" skills, to use folk tales, folk sports games, folk songs and "intelligence maps".

- The "mind map" of sensory channels helps to visualize how the brain receives and processes information, how the "imagination" is formed, and to develop the student's "creative thinking" skills.

\section{References}

1. Claire Gordon "Are you as smart as you think?" AST. Astrel M. 2004;

2. D. Medina "Brain Rules M. Publishing House. "Mann, Ivanov and Ferver" 2014;

3. B. Edwards Discover the artist in yourself. M. Potpourri. 2017;

4. V. Dubynin "The brain and sensory systems" You tube.com 21.04.2017;

5. Brain: Structure of function, general description. Golovai Mozg.ru;

6. A. Akimov "On the structure of the human eye, twilight vision and brain processing of impulses" You tube.com 2014;

7. V. Dubynin "Basic concepts that explain the chemical structure of the brain and the principles of neurotransmitters" You tube.com 02/27/2017;

8. Dopamine is a hormone of motivation and joy. The promise of happiness. garmonal.ru. 21.07.2018 y;

9. What is the dopamine hormone and how does it affect the body? my.worldwiki.com.;

10. E. D. Bono "Serious Creative Thinking" Mn.000 "Potpourri". 2005 year;

11. Ambidextr. Who is this. Psihomed.com.;

12. T. Buzan "Mind Maps" Moscow "Mann, Ivanov and Farmer" 2019 (p.105);

13. www.mindmap.com.;

14. www.mind mapping cannol.com.

15. A.G.Ganiyev and other. Using Mind Maps in Formation of imagination and creative thinking skills in 5-6 year old children. European Journal of Molecular \&Clinical Medicine. Volume7 Issue 112020 (339-343 p).

16. Ganiev A. G. and others. The role of travel lessons in the Shahrisabz Zoo in teaching foreign languages and developing their imagination to pupils of preschool educational institutions. International scientific and practical conference. Kazakhstan. Pavladar. 2020 year. (249-251).

17. A.G. Ganiev; S.N. Tashev; "The role of "Imagination" in the process of "Creative thinking". Developing students" "Imagination" and "Creative thinking" skills in teaching physics." Psychology and Education (2021) 58(1): 3569-3575 ISSN: 00333077.

18. A.G. Ganiev, Sh.A. Ganieva, Z.Sh. Abdunazarova; "Formation of "creative thinking" skills in 5-6year-old children with the help of mind maps". A Multidisciplinary Peer Reviewed Journal ISSN:2581-4230, Impact factor-7.223

19. A.G.Ganiev, T.D. Xudoyqulov, D.A.Maxmudov, M. Elboyeva,M.O.Abduraxmonov; Psychology and Education "A Mind map to show the place of the generations of the BABURIANS in the world civilization". (2021) 58(2): 3500-3504 ISSN:00333077

20. A.G. Ganiev; Philosophy and law is a socio-political, spiritual-enlightenment, philosophical-legal magazine; "The importance of developing students' creative thinking skills in the learning process". 2020/2 №16 